\title{
BMJ Open How is the organisational settings, content and availability of comprehensive multidisciplinary pulmonary rehabilitation for people with COPD in primary healthcare in Norway: a cross-sectional study
}

\author{
Bente Frisk (1) , ${ }^{1,2}$ Ingrid Elise Sundør, ${ }^{3}$ Mette Ramstad Dønåsen, ${ }^{3}$
} Olav Kåre Refvem, ${ }^{3}$ Christine Råheim Borge ${ }^{4,5}$

To cite: Frisk B, Sundør IE, Dønåsen MR, et al. How is the organisational settings, content and availability of comprehensive multidisciplinary pulmonary rehabilitation for people with COPD in primary healthcare in Norway: a crosssectional study. BMJ Open 2022;12:e053503. doi:10.1136/ bmjopen-2021-053503

- Prepublication history for this paper is available online. To view these files, please visit the journal online (http://dx.doi. org/10.1136/bmjopen-2021053503).

Received 17 May 2021 Accepted 21 January 2022

Check for updates

(C) Author(s) (or their employer(s)) 2022. Re-use permitted under CC BY-NC. No commercial re-use. See rights and permissions. Published by BMJ.

For numbered affiliations see end of article.

Correspondence to

Dr Bente Frisk;

bente.frisk@hvl.no

\section{ABSTRACT}

Objective To examine the organisational settings, content and availability of comprehensive multidisciplinary pulmonary rehabilitation (PR) programmes for people with chronic obstructive pulmonary disease (COPD) in primary healthcare in Norway.

Design This was a cross-sectional survey study examining the content, organisational settings and availability of comprehensive multidisciplinary PR for people with COPD.

Setting and participants When the survey was conducted, Norway had 436 municipalities/primary healthcare services who were invited to participate. Outcome measures The main outcome was the question related to accessibility to a PR programme in primary healthcare. We also examined in what degree the single interventions which are a part of a PR programme were one of the municipalities services and if there were regional differences regarding PR. Results Of the 436 municipalities, 158 answered the survey (36\% response rate), and the survey covered for $45 \%$ of the total population in Norway. Five per cent of the responders reported having multidisciplinary PR for patients with COPD. The most frequently reported single interventions that can be a part of a multidisciplinary PR programme were reported as follows: group exercise training for all diagnoses (27\%), reablement (25\%) and home-care treatment by a physiotherapist and/or occupational therapist (24\%). Southern-Eastern Norway had a significantly lower number of these interventions than Western Norway, Central Norway, and Northern Norway $(p<0.001)$.

Conclusion Only $5 \%$ of the Norwegian primary healthcare services (municipalities) had a multidisciplinary PR programme for patients with COPD. PR is the most important and cost-effective treatment within integrated care of patients with COPD. National strategies are therefore needed to increase the availability of PR for patients with COPD in Norwegian municipalities.
Strengths and limitations of this study

- This is the first study examining the availability of multidisciplinary pulmonary rehabilitation programs for people with COPD in Norwegian primary healthcare services/municipalities.

- Compared to previous surveys done in Norwegian municipalities, a response rate of $36 \%$ is high and a strength with this study.

- The study covered for $45 \%$ of the total population in Norway, and the whole country were represented.

- We did not have information if the most appropriate healthcare professionals completed the survey.

\section{INTRODUCTION}

Chronic obstructive pulmonary disease (COPD) is a highly prevalent chronic lung disease characterised by irreversible airflow limitation. ${ }^{1}$ In Norway, about 1 in 10 citizens have COPD, ${ }^{23}$ and more than 200000 are living with the disease. ${ }^{4}$ These high rates cause a major economic and societal burden. ${ }^{56}$

Dyspnoea and fatigue are the major daily symptoms experienced by patients with COPD and are usually the cause of exercise intolerance ${ }^{7-10}$ which leads to physical inactivity and reduced participation in activities of daily living. ${ }^{112}$ Over time, symptoms of fatigue, ${ }^{13}$ exercise intolerance, ${ }^{14-16}$ and physical inactivity $^{17-19}$ progress in patients receiving only usual COPD care. ${ }^{20-23}$

Pulmonary rehabilitation (PR) is defined as a comprehensive intervention based on a thorough patient assessment followed by tailored therapies that include, but are not limited to, education, exercise training and behaviour change. ${ }^{12} \mathrm{PR}$ is designed to improve the physical and psychological condition of people 
with chronic respiratory disease and to promote their long-term adherence to health-enhancing behaviours. ${ }^{12}$ Smoking cessation has the best capacity to influence the natural history of $\mathrm{COPD}^{1}$ and exercise training is considered to be a cornerstone in PR programme ${ }^{12}$ and both interventions are important non-pharmacological treatments in COPD. Clinically meaningful improvement in exercise tolerance, dyspnoea, fatigue, anxiety and depression, lower-limb muscle strength, self-efficacy, and health-related quality of life have been demonstrated after participation in PR, irrespective of the baseline clinical status. ${ }^{12}$ Guidelines highlight that PR is the most important treatment within the integrated care of patients with $\mathrm{COPD}^{124}$ and ranks as one of the most cost-effective treatment strategies. ${ }^{25}$

Despite the formal international definition of $\mathrm{PR},{ }^{12}$ there are large differences internationally, nationally and regionally in the setting, content, frequency, duration and organisational aspects of rehabilitative interventions. ${ }^{26}$ To date, most PR programmes in Norway have been performed in specialist healthcare service at hospital-based outpatient settings or in inpatient settings at specialised rehabilitation hospitals or centres. In 2012, the government in Norway introduced the Coordination reform ${ }^{27}$ to improve public health and healthcare services. The aim of the reform was to ensure that patients and users receive the right treatment at the right place and time near their home. The primary healthcare services (municipalities) were given the responsibility for providing rehabilitation, including PR, to their inhabitants. At the same time, PR rehabilitation availability in specialist healthcare was reduced in line with the reform. However, an evaluation of the reform demonstrated that the diagnosis-specific rehabilitation in the municipalities was reduced after $2012 .{ }^{28}$ On this background, we sought to provide an overview of the availability of PR in primary healthcare. Thus, the aim of this study was to examine the organisational settings, content and availability of comprehensive multidisciplinary PR programmes for people with COPD in Norwegian municipalities.

\section{METHODS}

\section{Study design and settings}

A cross-sectional survey of the content, organisational settings and availability of comprehensive multidisciplinary PR in Norwegian primary healthcare services were performed. The survey was distributed by a webpage (Questback) in February to April 2019. It comprised eight questions, and the response format was either a checkbox or free text option. The flowchart of the study is presented in figure 1 , and the questions are summarised in table 1.

The survey was developed by the Norwegian national COPD advisory board and was based on PR guidelines for patients with COPD, recommendations for PR, research related to PR and the evaluation of the Coordination reform. ${ }^{12} 28-30$ Before distribution of the survey, a pilot survey was performed on 20 random municipalities in

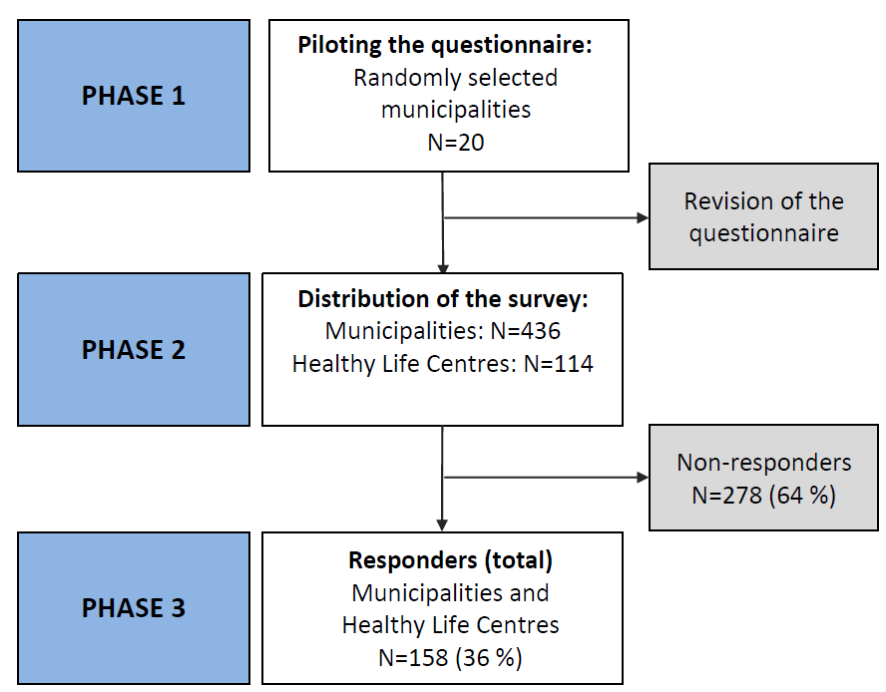

Figure 1 Flow chart of the study.

Norway to test whether the questions were interpreted as expected. Changes were made based on the comments from the participants in the pilot survey. Two questions from the pilot survey were removed in the revised version since the responders reported that the primary healthcare services did not have an earmarked budget for PR rehabilitation. The removed questions were (1) What is the total budget for PR for patients with COPD and (2) What percentage of the total rehabilitation budget constitutes a budget for PR rehabilitation. The revised version of the survey was distributed to the Norwegian primary healthcare services including the Healthy Life Centres through the official email addresses. The Healthy Life Centres are a part of the primary healthcare service in each municipality and offers effective, evidence-based measures for people with, or at high risk of, disease who need support for health behaviour change and coping with health problems and chronic disease. ${ }^{31}$ Figure 2 gives an overview of the Norwegian healthcare system. The administration office in the respective primary healthcare services forwarded the survey to the department of rehabilitation. For the Healthy Life Centres, the survey was distributed directly to each centre. Reminders were sent three times at 2-week interval after the first distribution.

The total number of inhabitants in Norway and the number of inhabitants from the responding primary healthcare services) and health authorities were obtained from Statistics Norway $^{32}$ at the time the survey was distributed.

\section{Statistical analyses}

The statistical analyses were performed using IBM SPSS Statistics software (V.25; IBM SPSS, Armonk, New York, USA), and figures were created in Excel 2016 (Microsoft, Redmond, Washington, USA). Descriptive statistics (mean, SD, frequencies and percentages) were used to characterise the primary healthcare services and the Healthy Life Centres. All variables were checked for normal distribution. 
Table 1 Pulmonary rehabilitation survey

Does the primary healthcare service have a section for coordination of rehabilitation?

1. $\square$ Yes $; \square$ No

2. Does the primary healthcare service offer and finance rehabilitation for patients with chronic obstructive pulmonary disease (COPD)?

$\square$ Yes $\square$ No

3. Do you have rehabilitation for other diseases? $\square$ Yes $\square$ No

4. Do you have pulmonary rehabilitation in collaboration with other primary healthcare services? $\square$ Yes $\square$ No

5. What types of rehabilitation programmes does your primary healthcare service offer?

$\square$ Multidisciplinary rehabilitation in nursing homes $\square$ Multidisciplinary rehabilitation over several weeks for patients with COPD

$\square$ Rehabilitation in everyday life

$\square$ Home-care treatment by a physiotherapist and/or occupational therapist for patients with COPD

$\square$ Self-management course for patients with COPD

$\square$ Smoking cessation course

$\square$ Group exercise training for patients with different diseases

$\square$ Water-based exercise training for patients with COPD

6. How are the patients recruited to rehabilitation?

$\square$ General practitioner

$\square$ Municipal emergency service

$\square$ Emergency medical service

$\square$ Specialist healthcare service

$\square$ Home-care health service

$\square$ The Norwegian Welfare and Administration Service

$\square$ Healthy Life Centres

$\square$ Free patient enrolment

$\square$ Other

7. Which professionals are responsible for the

rehabilitation programme?

$\square$ Physician

$\square$ Nurse

$\square$ Physiotherapist

$\square$ Occupational therapist

$\square$ Other

8. What are the most important reasons for not having rehabilitation for patients with COPD?

COPD, chronic obstructive pulmonary disease.

At the time when the survey was conducted, Norway was divided into 18 administrative regions, called counties, which contained 436 primary healthcare services/municipalities (after 1 January 2020, some of the municipalities and counties were merged). The counties are distributed into four regional health authorities: Northern Norway, Central Norway, Western Norway, and Southern-Eastern Norway (figure 3).

To analyse the response rate, the data were checked for duplicates, and any found were removed; for example, if

\section{Government}

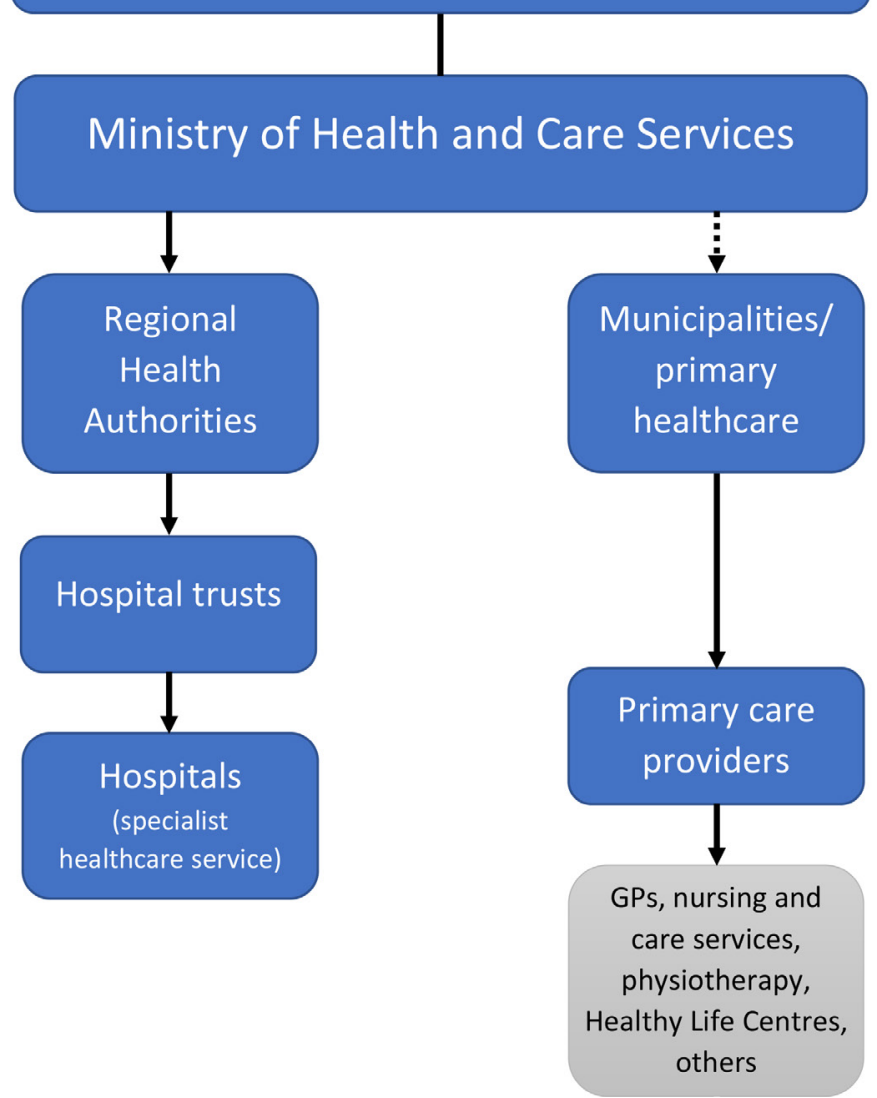

Figure 2 Overview of the Norwegian healthcare system. GPs, general practitioners.

Adtaped from: https://www.fhi.no/globalassets/ dokumenterfiler/rapporter/2014/hit-det-norskehelsesystemet-2013

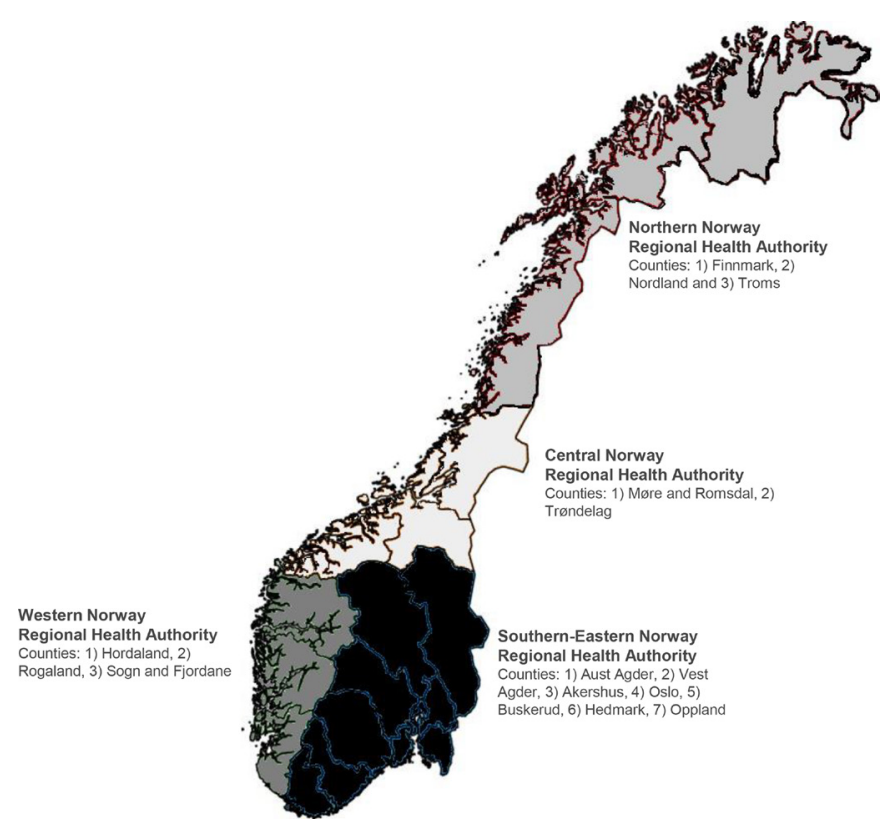

Figure 3 An overview of the regional health authorities and counties in Norway. 
both the primary healthcare service and the Healthy Life Centre from the same community healthcare services had answered the survey. The response rates from each of the four health regions were calculated based on the total number of possible answers from each region divided by the total number of inhabitants in Norway obtained from Statistics Norway ${ }^{32}$ at the time the survey was distributed.

A sum score of the reported interventions that can be a part of a PR programme was calculated. The different interventions categories in the survey were based on recommendations from international guidelines on $\mathrm{PR} .{ }^{12}$ The interventions were multidisciplinary rehabilitation, exercise training, home-care treatment by a physiotherapist and/or occupational therapist, water-based exercise training, smoking cessation and self-management courses. The sum score of the number of interventions that can be a part of a PR programme reported from the four health authorities (Northern Norway, Central Norway, Western Norway and Southern-Eastern Norway) were checked for normality with $\mathrm{Q}-\mathrm{Q}$ plot, and independent sample twotailed $t$ tests were used to analyse differences in the sum score. The significance level was set at $\mathrm{p}<0.05$.

\section{Patients and public involvement}

This project was designed by the National Advisory board for COPD (https://www.lhl.no/om-lhl/kolsradet/), and BF, CRB, IES and OKR are part of the board. The main goal for the National Advisory board for COPD is to increase the focus on COPD to improve diagnose, treatment and long-term follow-up of people with COPD. The board is multidisciplinary and consist of pulmonologists, physiotherapist, occupational therapist, nurse, physician and person diagnosed with COPD (user involvement). This study was initiated by the board, and the user in the board was an equal partner when designing the study. The results will be presented to the patient organisations, patients, government and the municipalities.

\section{RESULTS}

\section{Responders and organisational settings}

A total of 158 of 436 primary healthcare services/ municipalities answered the survey (36\% response rate) (figure 4). The response rates from the responding

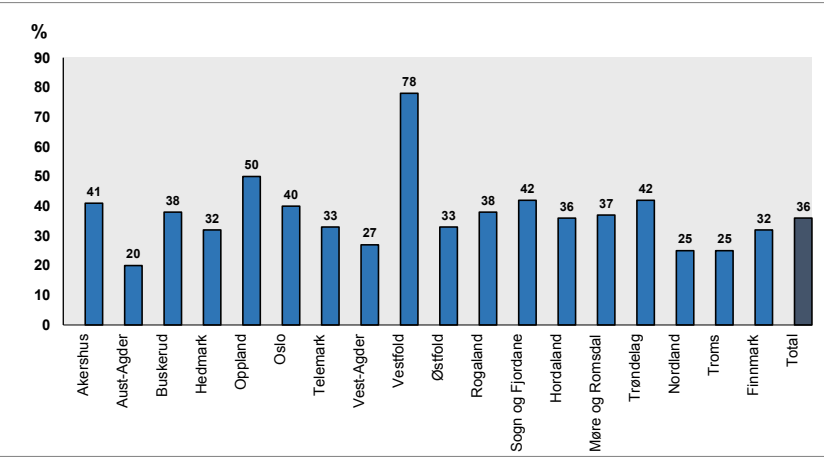

Figure 4 Response rates from the primary healthcare services presented by counties.

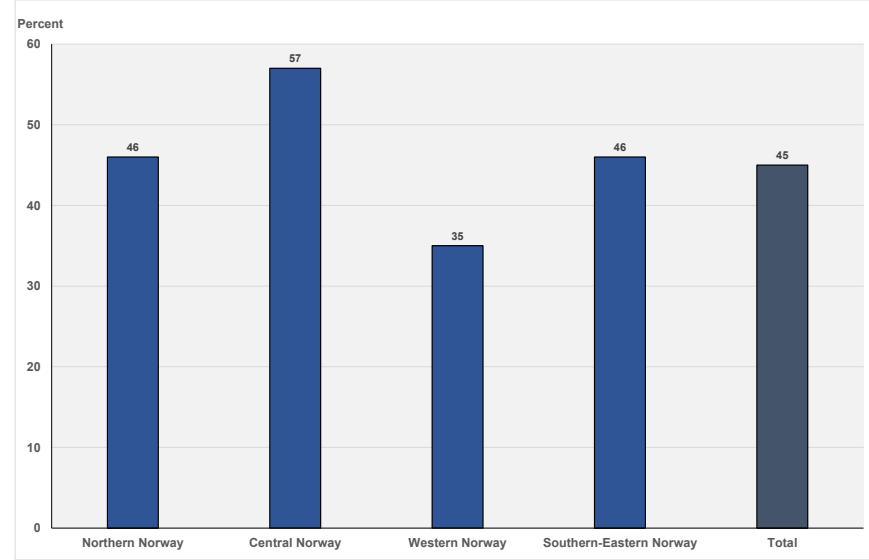

Figure 5 Coverage of the response rates of the survey presented as percentage of the total number of inhabitants in Norway and in the respective regional health authority.

primary healthcare services by counties ranged from $20 \%$ to $78 \%$ (figure 4 ). The total number of inhabitants in the responding primary healthcare services and the total population in Norway were 2391549 and 5328 212, respectively. The survey covered for $45 \%$ of the total population; the percentages for the four regions were Northern Norway $46 \%$, Central Norway $57 \%$, Western Norway $35 \%$ and Southern-Eastern Norway $46 \%$ (figure 5).

Of the responders, $77 \%$ reported having a section responsible for the coordination of rehabilitation, $35 \%$ had single interventions that can be a part of a PR programme and $15 \%$ had rehabilitation for other diagnosis (table 2). Further, 15\% provided rehabilitation programmes for diseases other than COPD, and 13\% provided PR in collaboration with other municipalities. The Healthy Life Centres reported $72 \%$ having a section responsible for coordination, $49 \%$ provided interventions that can be a part of a PR programme for patients with COPD, 23\% provided rehabilitation for other diseases than COPD and 19\% provided PR in collaboration with other municipalities.

The distribution as percentages of the total number of inhabitants in Norway is presented in figure 6 according to whether the four health authorities (1) had a section responsible for coordination of rehabilitation, (2) offered interventions that can be a part of a PR programme for COPD, (3) offered rehabilitation for other diseases than COPD and (4) collaboration between communities. In total from all the four health authorities $37 \%$ had a section responsible for coordination, $21 \%$ interventions that can be a part of a PR programme for patients with COPD, $11 \%$ provided rehabilitation for other diseases than COPD and $7 \%$ provided PR in collaboration with other municipalities.

\section{Rehabilitation interventions}

Rehabilitation interventions that were reported to be an available treatment in primary healthcare services are presented in figure 7 and included: multidisciplinary pulmonary rehabilitation over several weeks for patients 
Table 2 Overview of rehabilitation in Norwegian primary healthcare services among the responders

\begin{tabular}{|c|c|c|c|}
\hline & All & $\begin{array}{l}\text { Healthy Life } \\
\text { Centres }\end{array}$ & Municipalities \\
\hline & $n=165^{*}$ & $n=43$ & $n=119$ \\
\hline Section for & ordination & & \\
\hline Yes & $127(77)$ & 31 (72) & $96(79)$ \\
\hline No & $23(14)$ & $4(9)$ & $19(15)$ \\
\hline Missing & $15(9)$ & $8(19)$ & $7(6)$ \\
\hline PR comp. & COPD, n ( & & \\
\hline Yes & $57(35)$ & $21(49)$ & $36(29)$ \\
\hline No & $99(60)$ & $20(46)$ & $79(65)$ \\
\hline Missing & $9(5)$ & $2(5)$ & $7(6)$ \\
\hline Rehabilitat & for other $c$ & oses, n (\%) & \\
\hline Yes & $24(15)$ & $10(23)$ & $14(11)$ \\
\hline No & $73(44)$ & 10 (23) & $63(52)$ \\
\hline Missing & $68(41)$ & $23(54)$ & $45(37)$ \\
\hline Collaborati & between c & Iunities, n (\%) & \\
\hline Yes & $22(13)$ & $8(19)$ & 14 (12) \\
\hline No & $122(74)$ & 29 (67) & $93(76)$ \\
\hline Missing & $21(13)$ & $6(14)$ & 15 (12) \\
\hline
\end{tabular}

Pulmonary rehabilitation components: interventions that can be a part of a PR programme for patients with COPD.

*Seven duplicate answers from the municipalities and Healthy Life Centres in Northern Norway, two duplicates from Central Norway, four duplicates from Western Norway and one from Southern-Eastern Norway.

.COPD, chronic obstructive pulmonary disease; PR comp, pulmonary rehabilitation components.

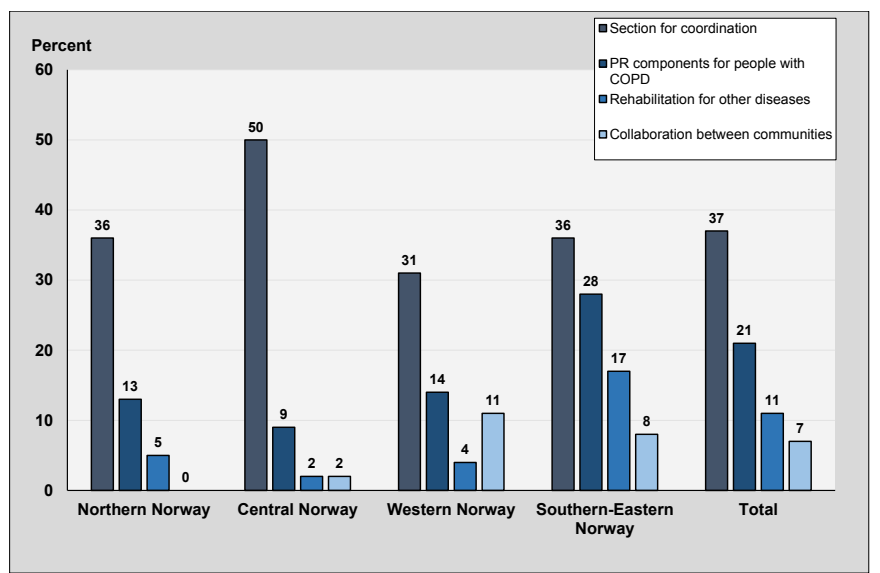

Figure 6 Coordination, interventions that can be a part of a PR programme, rehabilitation for other diseases and collaboration between communities presented as percentage of the total number of inhabitants in Norway in the four health authorities and for the total population. PR components are interventions that can be a part of a PR programme. COPD, chronic obstructive pulmonary disease; PR, pulmonary rehabilitation.

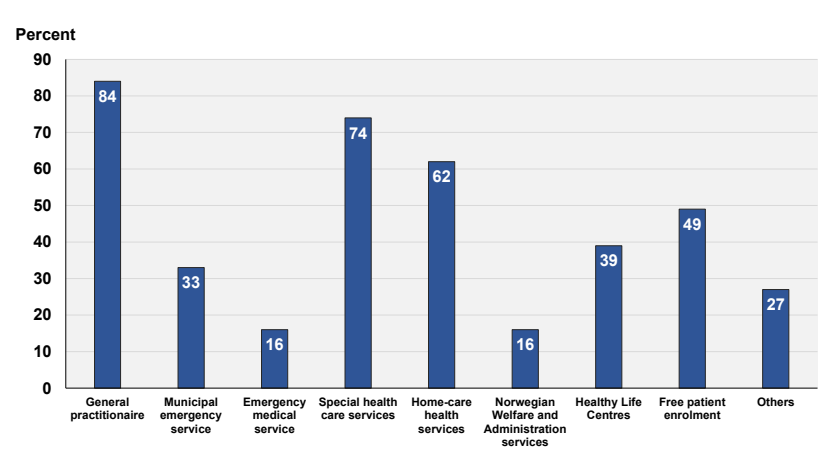

Figure 7 Components of rehabilitation interventions that were available in the responding primary healthcare services.

with COPD, multidisciplinary rehabilitation in nursing homes for all diagnoses, reablement, home-care treatment by a physiotherapist and/or occupational therapist, self-management courses for patients with COPD, group exercise training for all diagnoses, and water-based exercise training for patients with COPD and smoking cessation courses. Five per cent of the responders reported having multidisciplinary PR for patients with COPD and the most frequently reported interventions were group exercise training for all diagnoses (27\%), reablement $(25 \%)$ and home-care treatment by a physiotherapist and/or occupational therapist (24\%). On average, 2.9 ( $\mathrm{SD}=1.2$; range: $0-6)$ interventions were reported.

The mean differences between the rehabilitation components offered by the regional health authorities are presented in table 3. Southern-Eastern Norway had significantly fewer interventions (mean: 2.5; $\mathrm{SD}=1.2$ ) than the other three regional health authorities: mean 3.1 (1.1) in Western Norway $(\mathrm{p}<0.05)$, mean 3.5 (1.1) in Central Norway $(\mathrm{p}<0.001)$, and mean $3.2(1.1)$ in Northern Norway $(\mathrm{p}<0.05)$.

The survey included an open-ended question where those responders who did not offer multidisciplinary PR for patients with COPD could explain why. The most frequently reported reasons were lack of financing, low priority, no professional expertise, few inhabitants and therefore too few patients with COPD, and difficulties in differentiating between PR and other forms of rehabilitation.

\section{Referral sources and healthcare professionals involved in PR}

General practitioners (84\%), specialist healthcare services $(74 \%)$ and home-care services $(62 \%)$ were the most frequent referrals to the rehabilitation interventions in the municipalities (figure 8 ). The healthcare professionals responsible for the rehabilitation interventions were reported to be physiotherapists (26\%), physicians $(22 \%)$, nurses $(18 \%)$, occupational therapists $(2 \%)$ and others $(15 \%)$. 
Table 3 Number of pulmonary rehabilitation components available in the regional health authorities

\begin{tabular}{|c|c|c|c|c|c|c|c|c|}
\hline & \multirow[b]{2}{*}{$\mathbf{N}$} & \multirow{2}{*}{$\begin{array}{l}\text { Mean (SD, } \\
\text { min-max*) }\end{array}$} & \multicolumn{2}{|c|}{ Northern Norway } & \multicolumn{2}{|c|}{ Central Norway } & \multicolumn{2}{|c|}{ Southern-Eastern Norway } \\
\hline & & & Mean diff & $95 \% \mathrm{Cl}$ & Mean diff & $95 \% \mathrm{Cl}$ & Mean diff & $95 \% \mathrm{Cl}$ \\
\hline Northern Norway & 15 & $3.2(1.1,2-5)$ & & & & & & \\
\hline $\begin{array}{l}\text { Southern-Eastern } \\
\text { Norway }\end{array}$ & 56 & $2.5(1.2,0-6)$ & 0.72 & 0.01 to $1.42^{*}$ & 1.00 & 0.41 to $1.58^{\star *}$ & & \\
\hline Western Norway & 21 & $3.2(1.1,1-5)$ & 0.01 & -0.75 to 0.77 & 0.29 & -0.38 to 0.96 & 0.71 & 0.09 to $1.32^{*}$ \\
\hline
\end{tabular}

Data are presented as mean $\pm S D(S D)$ and were analysed using independent-sample t tests for continuous variables. Analyses were also done with Mann-Whitney $U$ test with the same results.

diff refers to the difference between the number of rehabilitation components in Northern Norway and the other three health authorities, respectively.

*min-max: minimum and maximum number of reported interventions.

\section{DISCUSSION}

This is the first national survey of organisational settings, content and availability of comprehensive multidisciplinary PR programmes in Norwegian municipalities. The main findings were that only $5 \%$ of the responding primary healthcare services had multidisciplinary PR programmes for people with COPD, and single interventions, which is part of a multidisciplinary PR programme, were reported by $35 \%$ of the responders which reflects $21 \%$ of the total populations in Norway, but these interventions were generic and not tailored to people with COPD.

International and national guidelines recommend multidisciplinary PR for people with $\mathrm{COPD}^{1229}$ and should include a combination of education, exercise training and strategies for behavioural change. Further, PR should be tailored to the individual patient's need, based on initial and ongoing assessments including disease severity, comorbidities and complexity. ${ }^{12}$ Even though PR is a highly effective treatment and a cornerstone of treatment for people with COPD, PR still remains underused across the world. ${ }^{33}$ In our study, the main reasons reported for not offering PR were lack of financing, low priority or no professional expertise. One possible reasons for this

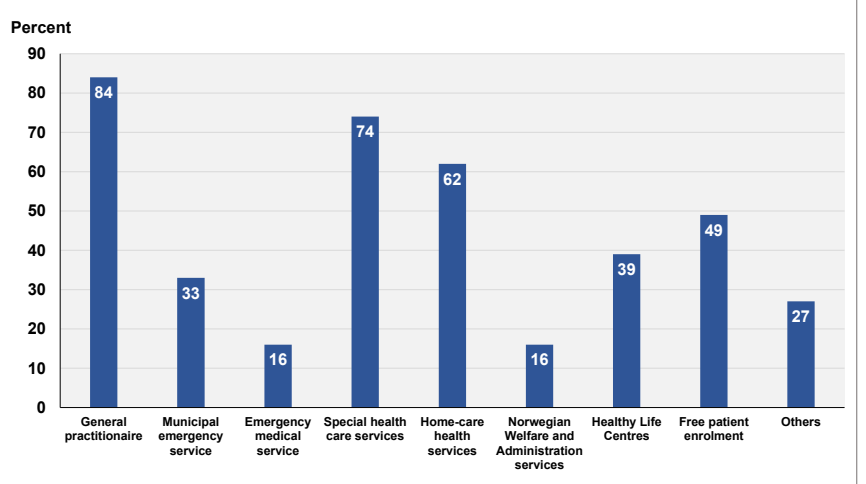

Figure 8 Referral resources to pulmonary rehabilitation components in the municipalities. COPD, chronic obstructive pulmonary disease. may be the government's fast change by transferring the responsibility for delivering PR from specialist healthcare to the municipalities as implemented in the Coordination reform in 2012. ${ }^{27}$ During the following years, PR for COPD in specialist healthcare was either reduced or closed. ${ }^{28}$

The competence to perform PR rehabilitation by healthcare professionals and the availability of this treatment has traditionally been delivered in specialist healthcare in Norway, but the availability has been, and still is scarce and the waiting time for the patients are up to 1 year. The United Nation's sustainable development goals: 'Ensuring equitable access to health services through universal health coverage based on stronger primary healthcare' addresses issues related to healthcare for patients with COPD. ${ }^{34}$ The aim of the Norwegian government strategy for non-communicable chronic diseases is to reduce morbidity and mortality from diseases such as COPD by $25 \%$ by $2025 .{ }^{35}$ To reach this goal, a combined range of services should include prevention, early diagnosis, systematic follow-up and treatment and rehabilitation. However, despite these goals, PR seems not to be readily available in Norwegian municipalities several years after implementation of the Coordination reform.

We found that the most common rehabilitation interventions were group exercise training for patients with different diseases, reablement, home-care treatment by a physiotherapist and/or occupational therapist, waterbased exercise for patients with COPD, multidisciplinary rehabilitation in nursing homes and smoking cessation. Of the municipalities that reported having PR for patients with COPD, the interventions were not multidisciplinary and often included only one type of treatment. It can therefore be questioned whether healthcare workers in the primary healthcare services have sufficient knowledge about the importance of, and how to perform PR, and if the government have done enough to support the municipalities in establishing PR for people with COPD.

PR programme that includes tailored exercise programme has been shown to improve exercise capacity, reduce symptoms such as dyspnoea, anxiety and depression and increase health-related quality of life. ${ }^{12}$ People with COPD respond to training differently from healthy 
people, ${ }^{36}$ and to improve exercise capacity, the training programme must be feasible for each patient and be designed to consider the physiological limitations following the disease. Non-diagnosis-specific group exercise training was reported as one of the most frequent interventions in the municipalities. Including people with different diagnoses and differences regarding functional problems in the same training group can make it difficult to provide tailored exercise that will lead to physiological improvements. Because of the latter, the Norwegian guidelines for COPD recommend the use of diagnosisspecific training in COPD. ${ }^{29}$

Home-care treatment by a physiotherapist and/or occupational therapist was provided by $24 \%$ of the responders in this study. In a randomised controlled trial, patients with stable COPD were randomly assigned to either a home-based model over 8 weeks delivered with minimal resources consisting of weekly telephone call and one visit by physiotherapist or a standard outpatient centre-based PR. ${ }^{37}$ The authors concluded that these two interventions produced equivalent short-term clinical outcomes and that a home-based model could be considered for people with COPD who cannot assess centre-based PR. ${ }^{37}$ The results from a systematic review with meta-analysis ${ }^{38}$ examining the impact of home-based PR concluded that homebased PR can be effective relieving respiratory symptoms, health-related quality of life and exercise capacity in patients with COPD, but more research with large-scale randomised controlled trials are needed to identify optimal standard home-based PR programme. Availability of PR was demonstrated to be scarce in the present study and is in line with findings from international studies, ${ }^{39} 40$ and to increase the accessibility to PR in primary healthcare it is necessary to consider alternative rehabilitation models, and home-based PR for those who cannot access outpatient clinics can be an alternative model to increase the accessibility to PR. Reablement was another intervention frequently reported by the responders, whereas the main goal is to improve daily activities. A Norwegian report stated that this intervention is associated with several positive experiences. ${ }^{41}$ However, improving exercise capacity and muscle strength is not the target of reablement, and the treatment is not adjusted for patients with different diagnoses. For patients with COPD, exercise training is the cornerstone of a PR programme, ${ }^{12}$ and reablement should not be the main intervention for these patients. ${ }^{41}$

Our survey showed that few of the municipalities $(6 \%)$ offered group self-management courses for patients with COPD. Self-management aim to provide knowledge and skills to help patients to improve their control over the disease and well-being, and to achieve behaviour change. These courses are not meant to be given as a single course but should include follow-up and assessments over time by a multidisciplinary team of healthcare professionals. ${ }^{42}$ Self-management is one of the main components of $\mathrm{PR}^{12}$ and should be provided in both group and individual basis, with focus on an individual action and treatment plan. Therefore, a greater focus on more individually tailored self-management courses and availability of PR programme is needed in the municipalities.

On average, an inpatient PR programme has a duration of 3-4 weeks and is often given as an outpatient programme over a longer period, such as 8 weeks, with rehabilitation sessions offered 2-3 times each week. ${ }^{43}$ However, our results showed that only $5 \%$ of the municipalities offered multidisciplinary PR over several weeks. This finding suggests that PR for people with COPD is a limited offered in Norwegian municipalities.

The most frequent referrals to rehabilitation in the municipalities were general practitioners $(84 \%)$, specialist healthcare $(74 \%)$ and home-care services $(62 \%)$. These data are consistent with those of Spruit $e t$ al, who found that general practitioners referred $73 \%$ of people with chronic respiratory disease to a PR programme and that self-referral was possible in $30 \%$ of the PR programmes. ${ }^{30}$ We found that $49 \%$ of responders reported free enrolment in the PR interventions. Referral from multidisciplinary team members (eg, physiotherapists, occupational therapists, nurses) working in the municipalities seems to be lacking in Norway.

Surprisingly, the municipalities in Southern-Eastern Norway had the fewest rehabilitation interventions than the other three health regions. However, SouthernEastern Norway has the highest population density. After adjusting for the total population in the region of Southern-Eastern Norway, PR was offered by more providers in this region than in the other three. In areas with low population density, it can be challenging to establish group rehabilitation. In Northern Norway, each primary healthcare service covers a large geographical area. For patients with chronic respiratory disease, it can be too challenging to travel long distance on a daily basis to participate in PR. Many of these patients have traditionally travelled to specialised rehabilitation hospitals for inpatient PR in either Northern or Southern-Eastern Norway.

Telehealth care may be an alternative way to incorporate PR into a primary healthcare service in Northern Norway. Hoaas et $a l^{44}$ examined whether physical activity levels were maintained 1 year after completion of a 2-year telerehabilitation intervention in people with COPD. The physical activity level decreased significantly after the intervention, which suggests that unsupervised home exercise might not be enough for maintaining physical activity level. ${ }^{44}$ Barriers to the use of telehealth for the follow-up of people with COPD include low interest, lack of knowledge and poor accessibility to the internet and e-health products. ${ }^{45}$ Thus, we need more evidence-based knowledge about different interventions and effects of telerehabilitation in people with COPD are needed. ${ }^{46}$

The municipalities reported several reasons for not being able to offer PR including the lack of resources and funding. This may be common reasons for lack of PR. ${ }^{26}$ To provide effective PR in the municipalities, it seems necessary for the government to provide the municipalities with more resources. Overall, our results raise 
the question of whether PR should be part of specialist healthcare rather than run by the primary healthcare services. Hospital-performed PR has been shown to have greater effects on disease-specific quality of life in people with COPD than PR performed in primary healthcare. ${ }^{43}$ Community-based PR has also been shown to cost more per session than PR in a hospital. ${ }^{47}$ In strict political and financial times, it is important to find rehabilitation models that are effective for patients in all stages of COPD. More studies are needed to compare the effectiveness of PR programme in primary and specialist healthcare. The definition of PR according to the American Thoracic Society/European Respiratory Society ${ }^{12}$ should be basis for all PR programmes.

\section{Strength and limitations}

The response rate in this survey was $36 \%$, and the responding municipalities covered for $45 \%$ of the total population in Norway. This represents nearly half of the population. Compared with similar studies, the response rate is good. The responding municipalities were representative of the whole country, and both urban and rural municipalities were represented. However, we acknowledge that our study results may be subject to selection bias. The survey was sent to the municipalities' official email address, and we could not ensure that the survey was forwarded to the right person/department. It is possible that the survey was not completed by the most appropriate healthcare professionals, and this could be a limitation.

In conclusion, PR is the most important and costeffective treatment in the integrated care of patients with COPD, and the results from this study showed that only $5 \%$ of the responding Norwegian primary healthcare services had a multidisciplinary $\mathrm{PR}$ programme for people with COPD. Single interventions which is a part of a multidisciplinary PR programme were reported by $35 \%$ of the responders which reflects $21 \%$ of the total populations in Norway, but these interventions were generic and not tailored to people with COPD.

The result from this study implies that the availability of PR was scarces in Norwegian municipalities, and national strategies are needed to increase this treatment for patients with COPD.

\section{Author affiliations}

${ }^{1}$ Department of Health and Functioning, Western Norway University of Applied Sciences, Bergen, Norway

${ }^{2}$ Department of Physiotherapy, Haukeland University Hospital, Bergen, Norway ${ }^{3}$ Landsforeningen for Hjerte- og Lungesyke, Jessheim, Norway

${ }^{4}$ Department of Interdisciplinary Health Sciences, University of Oslo, Oslo, , Norway

${ }^{5}$ Department of Research, Lovisenberg Diaconal Hospital, Oslo, Norway

Acknowledgements The authors wish to thank Ekstra Stiftelsen Helse og Rehabilitering (Stiftelsen Dam) for funding this project. We also would like to acknowledge the Norwegian municipalities which participated in the study.

Contributors BF conceptualised and designed the study, designed the data collection instruments, coordinated and supervised data collection, organised data, carried out analyses and drafted the initial manuscript and revised the manuscript. BF takes responsibility for the integrity of the data and accuracy of the data analysis and for the work and/or the conduct of the study, had access to the data, and controlled the decision to publish. IES conceptualised and designed the study, designed the data collection instruments, coordinated and performed data collection, reviewed the analyses and reviewed and revised the manuscript. MRD coordinated and performed data collection, reviewed the analyses and reviewed and revised the manuscript. OKR conceptualised and designed the study, designed the data collection instruments, reviewed the analyses and reviewed and revised the manuscript. CRB conceptualised and designed the study, designed the data collection instruments, coordinated and supervised data collection, organised data, carried out analyses and reviewed and revised the manuscript.

Funding This work was funded by the Ekstra Stiftelsen Helse og Rehabilitering (Stiftelsen Dam).

Map disclaimer The depiction of boundaries on this map does not imply the expression of any opinion whatsoever on the part of BMJ (or any member of its group) concerning the legal status of any country, territory, jurisdiction or area or of its authorities. This map is provided without any warranty of any kind, either express or implied.

\section{Competing interests None declared.}

Patient and public involvement Patients and/or the public were involved in the design, or conduct, or reporting, or dissemination plans of this research. Refer to the Methods section for further details.

\section{Patient consent for publication Not applicable.}

Ethics approval The study was presented to the Regional Ethics Committee in Southern-Eastern Norway and the Data Protection Officer of the National Association for Heart and Lung Diseases (www.Ihl.no). No approval for this study was needed because the study did not include information from individuals/ patients. However, we handled the data carefully to ensure anonymity for the participating municipalities and have presented the results according to the regions of Norway.

Provenance and peer review Not commissioned; externally peer reviewed.

Data availability statement Data are available upon reasonable request. All data relevant to the study are included in the article or uploaded as supplementary information. All data relevant to the study are included in the article, and no additional data are available. The data file with anonymized data can be made available to interested researchers upon reasonable request to Bente Frisk, providing Norwegian privacy legislation and GDPR are respected.

Open access This is an open access article distributed in accordance with the Creative Commons Attribution Non Commercial (CC BY-NC 4.0) license, which permits others to distribute, remix, adapt, build upon this work non-commercially, and license their derivative works on different terms, provided the original work is properly cited, appropriate credit is given, any changes made indicated, and the use is non-commercial. See: http://creativecommons.org/licenses/by-nc/4.0/.

ORCID iD

Bente Frisk http://orcid.org/0000-0002-7752-4895

\section{REFERENCES}

1 Global Initiative for Chronic Obstructive Lung Disease (GOLD). Global strategy for the diagnosis, management, and prevention of chronic obstructive pulmonary disease, 2021. Available: https://goldcopd. org/wp-content/uploads/2020/11/GOLD-REPORT-2021-v1.125Nov20_WMV.pdf

2 Johannessen A, Lehmann S, Omenaas ER, et al. Post-bronchodilator spirometry reference values in adults and implications for disease management. Am J Respir Crit Care Med 2006;173:1316-25.

3 Waatevik M, Skorge TD, Omenaas E, et al. Increased prevalence of chronic obstructive pulmonary disease in a general population. Respir Med 2013;107:1037-45.

4 et alLeivseth L, Husebø GR, Melbye H. Helseatlas kols, 2017. Available: https://docplayer.me/60784809-Helseatlas-kols-bruk-avhelsetjenester-ved-kronisk-obstruktiv-lungesykdom-i-helseatlas.html

5 Lopez AD, Shibuya K, Rao C, et al. Chronic obstructive pulmonary disease: current burden and future projections. Eur Respir J 2006;27:397-412.

6 Mathers CD, Loncar D. Projections of global mortality and burden of disease from 2002 to 2030. PLoS Med 2006;3:e442.

7 Guenette JA, Webb KA, O'Donnell DE. Does dynamic hyperinflation contribute to dyspnoea during exercise in patients with COPD? Eur Respir J 2012;40:322-9. 
8 Laveneziana P, Parker CM, O'Donnell DE. Ventilatory constraints and dyspnea during exercise in chronic obstructive pulmonary disease. Appl Physiol Nutr Metab 2007;32:1225-38.

9 O'Donnell DE, Guenette JA, Maltais F, et al. Decline of resting inspiratory capacity in COPD: the impact on breathing pattern, dyspnea, and ventilatory capacity during exercise. Chest 2012;141:753-62.

10 O'Donnell DE, Travers J, Webb KA, et al. Reliability of ventilatory parameters during cycle ergometry in multicentre trials in COPD. Eur Respir J 2009;34:866-74.

11 Nici L, Donner C, Wouters E, et al. American thoracic Society/ European respiratory Society statement on pulmonary rehabilitation. Am J Respir Crit Care Med 2006;173:1390-413.

12 Spruit MA, Singh SJ, Garvey C, et al. An official American thoracic Society/European respiratory Society statement: key concepts and advances in pulmonary rehabilitation. Am $J$ Respir Crit Care Med 2013;188:e13-64.

13 Peters JB, Heijdra YF, Daudey L, et al. Course of normal and abnormal fatigue in patients with chronic obstructive pulmonary disease, and its relationship with domains of health status. Patient Educ Couns 2011;85:281-5.

14 Tashkin DP, Celli B, Senn S, et al. A 4-year trial of tiotropium in chronic obstructive pulmonary disease. N Engl J Med 2008;359:1543-54

15 Vestbo J, Edwards LD, Scanlon PD, et al. Changes in forced expiratory volume in 1 second over time in COPD. N Engl $\mathrm{J}$ Med 2011;365:1184-92.

16 Polkey MI, Spruit MA, Edwards LD, et al. Six-minute-walk test in chronic obstructive pulmonary disease: minimal clinically important difference for death or hospitalization. Am J Respir Crit Care Med 2013:187:382-6.

17 Clarenbach CF, Sievi NA, Haile SR, et al. Determinants of annual change in physical activity in COPD. Respirology 2017;22:1133-9.

18 Koolen EH, van Hees HW, van Lummel RC, et al. "Can do" versus "do do": A Novel Concept to Better Understand Physical Functioning in Patients with Chronic Obstructive Pulmonary Disease. J Clin Med 2019;8:340.

19 Waschki B, Kirsten AM, Holz O, et al. Disease progression and changes in physical activity in patients with chronic obstructive pulmonary disease. Am J Respir Crit Care Med 2015;192:295-306.

20 Casanova C, Cote CG, Marin JM, et al. The 6-min walking distance: long-term follow up in patients with COPD. Eur Respir $J$ 2007;29:535-40.

21 Pinto-Plata VM, Cote C, Cabral H, et al. The 6-min walk distance: change over time and value as a predictor of survival in severe COPD. Eur Respir J 2004;23:28-33.

22 Spruit MA, Polkey MI, Celli B, et al. Predicting outcomes from 6-minute walk distance in chronic obstructive pulmonary disease. $J$ Am Med Dir Assoc 2012;13:291-7.

23 Frisk B, Espehaug B, Hardie JA, et al. Physical activity and longitudinal change in 6-min walk distance in COPD patients. Respir Med 2014;108:86-94.

24 National Institue for Health and Care Excellence (NICE) guidelines. Chronic obstructive pulmonary disease in over 16S: diagnosis and management, 2019. Available: https://www.nice.org.uk/guidance/ ng115/chapter/Recommendations\#managing-stable-copd2019

25 Zoumot Z, Jordan S, Hopkinson NS. Emphysema: time to say farewell to therapeutic nihilism. Thorax 2014;69:973-5.

26 Spruit MA, Wouters EFM. Organizational aspects of pulmonary rehabilitation in chronic respiratory diseases. Respirology 2019;24:838-43.

27 St.meld. nr 47 (2008-2009). Samhandlingsreformen - Rett behandling - på rett sted- til rett tid: Helse- og omsorgsdepartementet; 20082009. Available: https://www.regjeringen.no/no/dokumenter/stmeldnr-47-2008-2009-/id567201/
28 The Research Council of Norway. Evaluering AV samhandlingsreformen (evaluation of the coordination reform): the Research Council of Norway, 2016. Available: https://www. forskningsradet.no/om-forskningsradet/publikasjoner/2016/ evaluering-av-samhandlingsreformen/

29 Helsedirektoratet. KOLS: Nasjonal faglig retningslinje OG veileder for forebygging, diagnostisering OG oppfølging. Available: https:// helsedirektoratet.no/Lists/Publikasjoner/Attachments/847/Nasjonalfaglig-retningslinje-og-veileder-for-forebygging-diagnostisering-ogoppf\%C3\%B8lging-IS-2029.pdf2012

30 Spruit MA, Pitta F, Garvey C, et al. Differences in content and organisational aspects of pulmonary rehabilitation programmes. Eur Respir J 2014;43:1326-37.

31 Helsedirektoratet. Healthy life centres in Norway. Available: https:// www.helsedirektoratet.no/english/healthy-life-centres

32 Statistics Norway. Available: https://www.ssb.no/statbank/table/ 01223/

33 Holland AE, Cox NS, Houchen-Wolloff L, et al. Defining modern pulmonary rehabilitation. An official American thoracic Society workshop report. Ann Am Thorac Soc 2021;18:e12-29.

34 United Nations. Sustainable development goals, 2019. Available: https://www.un.org/sustainabledevelopment/sustainabledevelopment-goals/;

35 Norwegian Ministry of Health and Care Services. NCD-Strategy 2013-2017, 2013. Available: https://www.regjeringen.no/ contentassets/e62aa5018afa4557ac5e9f5e7800891f/ncd_strategy 060913.pdf

36 Gloeckl R, Marinov B, Pitta F. Practical recommendations for exercise training in patients with COPD. Eur Respir Rev 2013;22:178-86.

37 Holland AE, Mahal A, Hill CJ, et al. Home-Based rehabilitation for COPD using minimal resources: a randomised, controlled equivalence trial. Thorax 2017;72:57-65.

38 Liu X-L, Tan J-Y, Wang T, et al. Effectiveness of home-based pulmonary rehabilitation for patients with chronic obstructive pulmonary disease: a meta-analysis of randomized controlled trials. Rehabil Nurs 2014;39:36-59.

39 Brooks D, Sottana R, Bell B, et al. Characterization of pulmonary rehabilitation programs in Canada in 2005. Can Respir $J$ 2007;14:87-92.

40 Yohannes AM, Connolly MJ. Pulmonary rehabilitation programmes in the UK: a national representative survey. Clin Rehabil 2004:18:444-9

41 Førland O, Skumsnes R. Hverdagsrehabilitering-En oppsummering AV kunnskap, 2016.

42 Jordan RE, Majothi S, Heneghan NR, et al. Supported selfmanagement for patients with moderate to severe chronic obstructive pulmonary disease (COPD): an evidence synthesis and economic analysis. Health Technol Assess 2015;19:1-516.

43 McCarthy B, Casey D, Devane D, et al. Pulmonary rehabilitation for chronic obstructive pulmonary disease. Cochrane Database Syst Rev 2015:CD003793

44 Hoaas $\mathrm{H}$, Morseth $\mathrm{B}$, Holland $\mathrm{AE}$, et al. Are physical activity and benefits maintained after long-term Telerehabilitation in COPD? Int $J$ Telerehabil 2016;8:39-48.

45 Vitacca M, Montini A, Comini L. How will telemedicine change clinical practice in chronic obstructive pulmonary disease? Ther Adv Respir Dis 2018;12:1753465818754778.

46 Selzler A-M, Wald J, Sedeno M, et al. Telehealth pulmonary rehabilitation: a review of the literature and an example of a nationwide initiative to improve the accessibility of pulmonary rehabilitation. Chron Respir Dis 2018:15:41-7.

47 Waterhouse JC, Walters SJ, Oluboyede Y, et al. A randomised 2 X 2 trial of community versus Hospital pulmonary rehabilitation, followed by telephone or conventional follow-up. Health Technol Assess 2010;14:i-v, vii-xi, 1-140. 